\title{
Pengembangan Lembar Kerja Peserta Didik Berbasis Keterampilan Proses Sains pada Materi Larutan Eleketrolit dan Nonelektrolit
}

\author{
Nova Citra, Masriani, Lukman Hadi, Rody Putra Sartika, Maria Ulfah \\ Jurusan P. MIPA, FKIP Universitas Tanjungpura \\ masriani@fkip.untan.ac.id \\ lukmanhadi.thesis@gmail.com
}

\begin{abstract}
This study aims to develop student worksheet based on science process skills and to determine the level of feasibility and teacher response to the developed student worksheet. The form of this research model is research and development $(R \& D)$ with reference to the ADDIE development model modified into ADD, namely Analysis, Design and Development. The subjects of this study were student worksheet and the responses of 3 chemistry teachers at SMA Kubu Raya. The data collection instrument used was the assessment sheet. the feasibility of the material, language, and graphics as well as the teacher's response questionnaire. The results of data processing show that the developed student worksheet is very suitable for use in learning electrolyte and non-electrolyte solutions in terms of the feasibility of material, language, and graphics with a percentage of $98.2 \%$ with a very feasible category. Based on the calculation of the teacher response questionnaire to the science process skills based student worksheet, it shows that the teacher response is very good with a percentage of 93\%. Thus, science process skills based student worksheet is very suitable to be used in the learning process.
\end{abstract}

Keywords : Student worksheet, Science process skills, Electrolyte and non-electrolyte solutions This is an open access article distributed under the Creative Commons 4.0 Attribution License, which permits unrestricted use, distribution, and reproduction in any medium, provided the original work is properly cited. $@ 2021$ by author

\section{PENDAHULUAN}

Ilmu kimia merupakan salah satu cabang sains yaitu ilmu yang mencari jawaban atas pertanyaan apa, mengapa, dan bagaimana terkait gejala-gejala alam yang berhubungan dengan komposisi, struktur dan sifat perubahan, dinamika, dan energetika zat yang melibatkan keterampilan dan penalaran. Penerapan pembe lajaran kimia tidak hanya untuk menguasai pengetahuan kimia sebagai produk, tetapi juga untuk menguasai sikap dan proses ilmiah. Oleh sebab itu, untuk memahami hakikat ilmu kimia secara utuh, pembelajaran kimia perlu menggu nakan keterampilan proses sains (Ardhiaiantari \& Kadaritna, 2015).

Berdasarkan Permendikbud tahun 2016, K13 hanya menerapkan pendekatan saintifik. Pendekatan ini ditandai dengan adanya proses saintifik atau ilmiah selama proses pembe lajaran. Proses saintifik yang dimaksud tergam bar dalam proses pembelajaran yang melibatkan kegiatan peserta didik berupa mengobservasi, menanya, mengumpulkan data, mengasosiasi, menyimpulkan dan mengkomunikasikan. Kegiat an saintifik tersebut berkaitan dengan KPS. Keterampilan yang dimaksud terdiri atas kete rampilan observasi, klaifikasi, merumuskan pertanyaan, menyusun hipotesis, merencanakan percobaan, memilih alat bahan percobaan, menggunakan alat bahan, memprediksi, inter prestasi, dan mengkomunikasikan (Tawil \& Diella, 2019)

Pembelajaran sains dengan pendekatan keterampilan proses dapat melatih dan mengem bangkan kemampuan berpikir siswa. Keteram pilan proses sains (KPS) memiliki pengaruh yang besar pada pendidikan sains karena keterampilan ini membantu siswa untuk mengembangkan keterampilan mental yang lebih tinggi seperti berfikir kritis, pengambilan keputusan dan pemecahan masalah (Karsli \& Sahin, 2009).

Pengalaman belajar perlu dilatih melalui pembelajaran. Menurut Ango (2002), penga laman belajar peserta didik harus melatihkan keterampilan proses seperti mengamati, meng klasifikasikan dan memprediksi, mengiferensi, dan berkomunikasi. Keterampilan ini sangat 
penting untuk membangun pemahaman konsep ilmiah siswa yang bermanfaat dan bermakna. Selain itu, pengalaman tersebut merupakan hal yang penting agar siswa dapat menggunakan proses ilmiah dalam memecahkan masalah dan menerapkannya dalam kehidupan sehari-hari.

KPS merupakan instrumen sekaligus kaidah berpikir (ways of thinking) yang diguna kan oleh siswa untuk memperoleh keahlian dalam sains, sehingga penggunaan KPS dalam pembelajaran tidak hanya membantu siswa untuk membentuk atau membangun pengetahu an, tetapi KPS juga akan membantu siswa untuk mengembangkan proses kognitif dan berpikir siswa (Firdaus \& Mirawati, 2016). Menurut Firdaus (2016) KPS merupakan alat untuk menyelasaikan masalah dan mengembangkan keterampilan berpikir tingkat tinggi (higher order thinking skills) siswa, seperti keterampilan berpikir kritis.

Guru dalam menyiapkan proses pembela jaran tidak dapat terlepas dari beragam perangkat pembelajaran. Salah satu perangkat pembelajaran yakni lembar kerja peserta didik (LKPD). LKPD merupakan alat bantu dalam mengarahkan kegiatan belajar peserta didik. Komponen LKPD terdiri atas judul, alokasi, waktu, tujuan pembelajaran, ringkasan materi esensial, dan prosedur kegiatan belajar yang harus dilakukan. Umumnya guru menggunakan LKPD yang terdapat dalam buku belajar peserta didik. Umumnya guru menggunakan LKPD yang terdapat dalam buku belajar peserta didik. Dengan kata lain LKPD itu dibuat oleh orang lain sehingga guru kurang terampil dalam menyusun LKPD yang sesuai dengan kondisi dan kebutuhan peserta didik.

Salah satu perangkat pembelajaran yang dapat digunakan untuk mengembangkan keterampilan proses sains siswa adalah LKPD. LKPD berisi pedoman bagi peserta didik untuk melakukan kegiatan yang mencerminkan keterampilan proses sains sehingga peserta didik memperoleh pengetahuan dan keterampilan yang perlu dikuasainya. Melalui LKPD siswa dimotivasi untuk lebih kreatif menemukan jawaban atas keingitahuannya dan meningkat kan kemampuan berpikir, mengobservasi, meng interpretasi, dan mengkomunikasikan serta berbagai aktivitas lainnya (Muida, 2019; Asrizal, 2019). LKPD dapat meningkatkan keefektifan siswa dalam proses pembelajaran dengan memberi kesempatan kepada siswa untuk melakukan kegiatan kerja secara perorangan ataupun secara kelompok dalam menyelesaikan tugas yang diberikan.

Kenyataan di lapangan menunjukkan bahwa LKPD yang banyak beredar di sekolah saat ini belum berperan secara maksimal dalam melatih dan mengembangkan KPS siswa. Langkah-langkah yang disajikan dalam LKPD kurang melatih siswa melakukan proses ilmiah, menganalisis dan menemukan suatu konsep. LKPD belum bisa digunakan untuk mencari atau menemukan suatu konsep dan mengaplikasikan konsep yang sudah ada dalam. Salah satu cara mengatasi kesulitan belajar siswa adalah dengan memberikan media pembelajaran yang sesuai. Pembelajaran yang dapat membuat siswa aktif untuk menemukan pengetahuannya sendiri dengan mengembangkan kemampuannya dan kemandiriannya (Fitriyani et al., 2019). Penggu naan LKPD berbasis KPS sangat efektif dalam proses pembelajaran karena dapat meningkatkan hasil belajar, meningkatkan pemahaman konsep, dapat menarik minat peserta didik dalam pembelajaran (Muida, 2019).

Larutan elektrolit dan nonelektrolit adalah salah satu materi kimia yang diajarkan di kelas $\mathrm{X}$ SMA. Materi yang mencakup pengetahuan konseptual, faktual, dan prosedural. Siswa merasa kesulitan mempelajari materi ini karena materi ini sifat arus listrik yang kurang dipahami oleh siswa. Kesulitan siswa mempelajari larutan elektrolit disebabkan karena materi yang bersifat mikroskopik sehingga tidak dapat dibayangkan oleh siswa. Salah satu cara mengatasi kesulitan belajar siswa adalah dengan memberikan media pembelajaran yang sesuai. Pembelajaran yang dapat membuat siswa aktif untuk menemukan pengetahuannya sendiri dengan mengem bangkan kemampuamnya dan kemandiriannya (Fitriyani et al., 2019).

Pengalaman secara langsung dapat di wujudkan dengan adanya media pembelajaran yang berisi panduan untuk peserta didik dalam melaksanakan kegiatan ilmiah atau pemecahan masalah serta latihan soal. Kehadiran media diharapkan dapat mempermudah peserta didik dalam memahami ilmu yang dipelajarinya. Salah satu media pembelajaran ialah Lembar Kerja Peserta Didik (LKPD). LKPD adalah panduan peserta didik yang digunakan untuk melakukan kegiatan penyelidikan atau pemecah an masalah (Marsa et al., 2016).

Pengembangan LKPD berbasis keteram pilan proses sains pada materi larutan elektrolit dan non elektrolit diharapkan dapat membantu 
guru untuk melatih keterampilan proses siswa, sehingga kemampuan pemahaman konsep dan keterampilan berpikir tingkat tinggi siswa juga dapat berkembang dengan baik. Penggunaan LKPD berbasis KPS terbukti dapat meningkat kan hasil belajar, meningkatkan pemahaman konsep dan memotivasi peserta didik dalam proses pembelajaran (Rahmatillah et al., 2017). Adapun tujuan penelitian untuk menentukan tingkat kelayakan LKPD dan menentukan timgkat respon guru terhadap LKPD berbasis KPS pada materi larutan elektrolit dan nonelektrolit untuk guru SMA KubuRaya.

\section{METODE PENELITIAN}

Jenis penelitian ini merupakan penelitian Research and Development (R\&D). Produk yang dihasilkan berupa LKPD berbasis KPS pada materi larutan elektrolit dan nonelektrolit Model pengembangan yang digunakan mengacu pada model penelitian dan pengembangan ADDIE. Tahapan pengembangan perangkat pembelajaran dengan model ADDIE dapat diperhatikan pada Gambar 1.

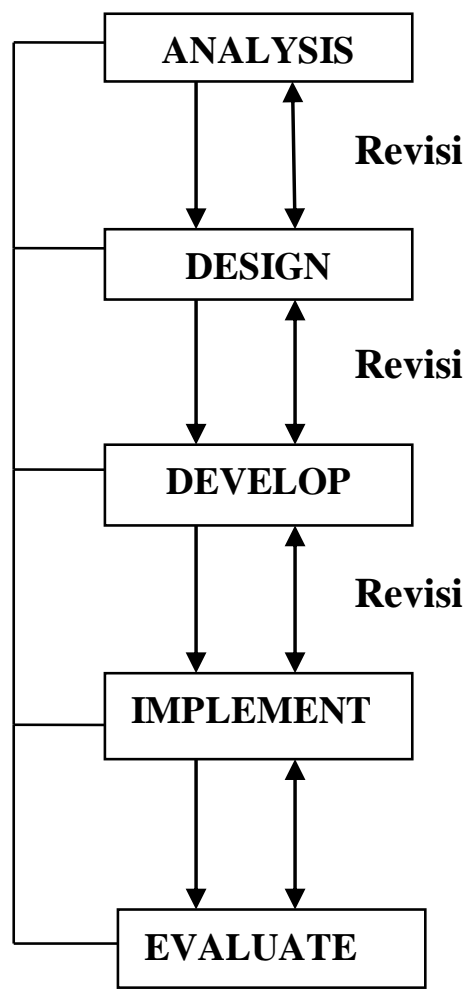

Gambar 1. Pengembangan Media Pembelajaran LKPD berbasis KPS

LKPD merupakan salah satu sarana untuk membantu dan mempermudah dalam kegiatan pembelajaran sehingga akan akan terbentuk interaksi yang efektif anatara peserta didik dengan guru, dan dapat meningkatkan aktivitas peserta didik dalam peningkatan prestasi belajar. Hal ini sejalan dengan Hosnan dalam Marsa et al (2016).

Penelitian ini bertujuan untuk menghasil kan sebuah produk yaitu LKPD berbasis keterampilan proses sains. Dalam penelitian ini mengacu pada model penelitian dan pengem bangan ADDIE yang meliputi analisis, desain, pengembangan, implementasi, dan evaluasi. Analisis analisis (analyze) terdiri atas analisis kebutuhan dan analisis kurikulum). Kegiatan desain (design) meliputi penentuan KD dan indikator pembelajaran serta rancangan instru ment. Kegiatan pengembangan (development) mencakup validasi ahli atau praktisi, validasi kelayakan materi, validasi kelayakan bahasa, dan validasi kelayakan grafik. Kegiatan imple mentasi (implementation) terdiri atas penyiapan guru, penyiapan siswa, dan uji coba lapangan. Kegiatan evaluasi (evaluation) mencakup eva luasi formatif yang dilakukan pada setiap tahap dan kegiatan evaluasi sumatif. Tahap dari model ADDIE yang dimodifikasi menjadi ADD hanya sampai tahap development.

Pelaksanaan kegiatan penelitian dilakukan berdasarkan tahapan dari ADDIE. Tahap pertama adalah analisis. Pada analisis dilakukan untuk mengumpulkan informasi mengenai masalah-masalah yang muncul pada kegiatan pembelajaran melalui wawancara dengan guru dan mengidentifikasi kemungkinan solusi yang dapat digunakan untuk mengatasi masalah yang terjadi. Pada tahap ini dilakukan beberapa analisis sebagai berikut : (a) analisis kebutuhan, bertujuan untuk mengumpulkan data terkait masalah yang dihadapi dalam pembelajaran di sekolah dan (b) analisis kurikulum, dilakukan dengan memperhatikan karakteristik kurikukum yang sedang digunakan di sekolah. Hal ini dilakukan agar pengembangan yang dilakukan sesuai dengan tuntutan kurikulum yang diguna kan. Tahap kedua adalah tahap desain. Pada tahap ini dilakukan perancangan media pembe lajaran berupa LKPD berbasis KPS yang di desain dan disesuaikan dengan kompetensi inti, kompetensi dasar, dan indikator pencapaian. Tahap ketiga adalah tahap pengembangan. Pada tahap ini dilakukan (a) validasi desain ahli, (b) revisi desain, (c) uji respon guru, dan (d) penyempurnaan produk akhir.

Subjek pada penelitian ini adalah lembar kerja peserta didik berbasis keterampilan proses sains pada materi larutan elektrolit dan 
nonelektrolit Uji kelayakan pada ahli dan juga uji respon guru di sekolah. Teknik dan alat pengumpulan data pada penelitian ini adalah wawancara, observasi, lembar validasi dan angket respon guru. Sebelum angket diberikan, angket divalidasi terlebih dahulu untuk diketahui reabilitas angket agar layak digunakan sebagai instrumen penelitian.

Penilaian kelayakan media dilakukan oleh 9 orang validator yang terdiri dari ahli bahasa, materi, dan grafik. Ahli dalam penelitian ini adalah ahli yang merupakan dosen pendidikan kimia Universitas Tanjungpura, dosen Pendidik an pendidikan kimia Universitas Tanjungpura, dosen Pendidikan Bahasa Indonesia, dosen Institute Agama Islam Negeri, dosen Universitas Muhammadiyah. Pengolahan data angket penilai an media dan angket respon guru dengan menghitung frekuensi skor penilaian tiap respon, menghitung skor total tiap respon, menghitung persentase perolehan skor tiap respon, meng hitung persentase total dan menentukan kriteria respon. Angket penilaian kelayakan media dan angket respon guru menggunakan skala Likert. Skala Likert pada angket penilaian kelayakan yaitu sangat tidak layak (1), tidak layak (2), layak (3), sangat tidak layak (4), sedangkan pada angket respon guru disajikan pada Tabel berikut.

Tabel 1. Skor Skala Likert Respon Guru

\begin{tabular}{ccc}
\hline Kategori & $\begin{array}{c}\text { Pernyataan } \\
\text { Positif }\end{array}$ & $\begin{array}{c}\text { Pernyataan } \\
\text { Negatif }\end{array}$ \\
\hline SS & 4 & 1 \\
S & 3 & 2 \\
TS & 2 & 3 \\
STS & 1 & 4 \\
\hline
\end{tabular}

(Riduwan, 2015)

Teknik pengumpulan data, dibagi menjadi data primer dan data sekunder. Menurut Rahmatillah et al., (2017), data primer adalah data yang di dapat dan dikumpulkan di lapangan oleh peneliti. Data primer yang didapat dapat menggunakan wawancara, observasi, dan angket yang diberikan kepada ahli berupa angket kelayakan materi, bahasa, dan kegrafikan serta angket respon guru sedangkan data sekunder di dapat dan dikumpulkan oleh peneliti dari datadata yang sudah ada sebelumnya serta di gunakan untuk mendukung informasi primer yang telah dikumpulkan seperti bahan pustaka, literatur maupun buku.

Alat pengumpul data pada penelitian ini yaitu lembar penilaian kelayakan LKPD berbasis keterampilan proses sains pada materi larutan elektrolit dan nonelektroit. Hal ini bertujuan untuk mengetahui pendapat atau masukan ahli terhadap produk yang dikembang kan sebelum diuji cobakan dalam pembelajaran. Penelitian ini menggunakan skala likert dengan skala penilaian sangat baik, baik, kurang baik, dan tidak baik untuk setiap butir pernyataan. Kemudian untuk keperluan analisis kuantitatif maka skala itu diberi skor pada lembar penilaian kelayakan yaitu skor 1 (tidak baik), skor 2 (kurang baik ), skor 3 (baik) dan skor 4 (sangat baik). Angket respon guru terhadap LKPD berbasis keterampilan proses sains pada materi larutan elektrolit dan nonelektrolit. Skala yang digunakan pada angket ini adalah skala likert dengan empat skala penilaian (kriteria), yaitu SS (sangat setuju), S (setuju), TS (tidak setuju), dan STS (sangat tidak setuju). Pengisan angket ini dilakukan saat uji coba lapangan untuk menge tahui respon guru terhadap lembar kerja peserta didik yang dikembangkan, sebelum diberikan kepada guru angket ini terlebih dahulu divalidasi agar angket tersebut valid dan layak digunakan sebagai instrumen dalam penelitian.

\section{HASIL DAN PEMBAHASAN}

Penelitian ini bertujuan untuk menghasil kan sebuah lembar kerja peserta didik berbasis keterampilan proses sains. dalam penelitian ini sebagai berikut: Berdasarkan hasil penilaian kelayakan pada LKPD berbasis KPS layak digunakan dalam pembelajaran.Penilaian kela yakan media mencakup tiga aspek penilaian yaitu aspek bahasa, media, dan materi. Selain memberikan penilaian, validator juga memberi kan saran ataupun masukan-masukan terhadap LKPD berbasis KPS. Berdasarkan masukanmasukan dan saran terhadap LKPD berbasis KPS dilakukan revisi pada pengembangan LKPD berbasis KPS sebelum dilakukan penilai an respon. Aspek-aspek penilaian LKPD berbasis KPS adalah sebagai berikut.

\section{Ahli Bahasa}

Kesesuaian dengan kaidah bahasa Indonesia yang dimaksud dengan kesesuai dengan kaidah bahasa adalah mengacu pada pedoman Umum Ejaan Bahasa Indonesia 
(PUEBI). Perbaikan disajikan pada gambar dan terdapat perbaikan kalimat.

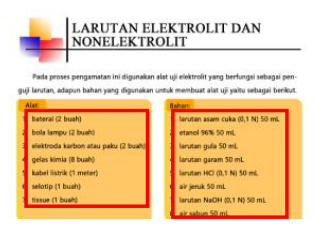

Sebelum revisi

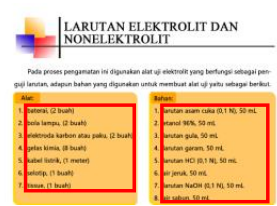

Sesudah
Gambar 2. Revisi Bagian Alat dan Bahan

Dari Gambar 2 dapat dijelaskan bahwa hasil revisi bagian alat dan bahan yang ada di dalam LKPD, berdasarkan saran ahli bahasa sebelum direvisi penulisan alat dan bahan menggunakan tanda (,) kemudian direvisi ahli bahasa penulisan alat dan bahan tidak perlu menggunakan tanda koma. Penilaian ahli bahasa dilakukan untuk menentukan tingkat kelayakan bahasa pada lembar kerja peserta didik berbasis keterampilan proses sains. Ahli bahasa akan memberikan penilai an dan komentar maupun saran pada lembar instrumen yang telah diberikan oleh peneliti. Validasi kelayakan bahasa dilakukan oleh 3 orang ahli bahasa.

Tabel 2. Hasil Penilaian Kelayakan Bahasa

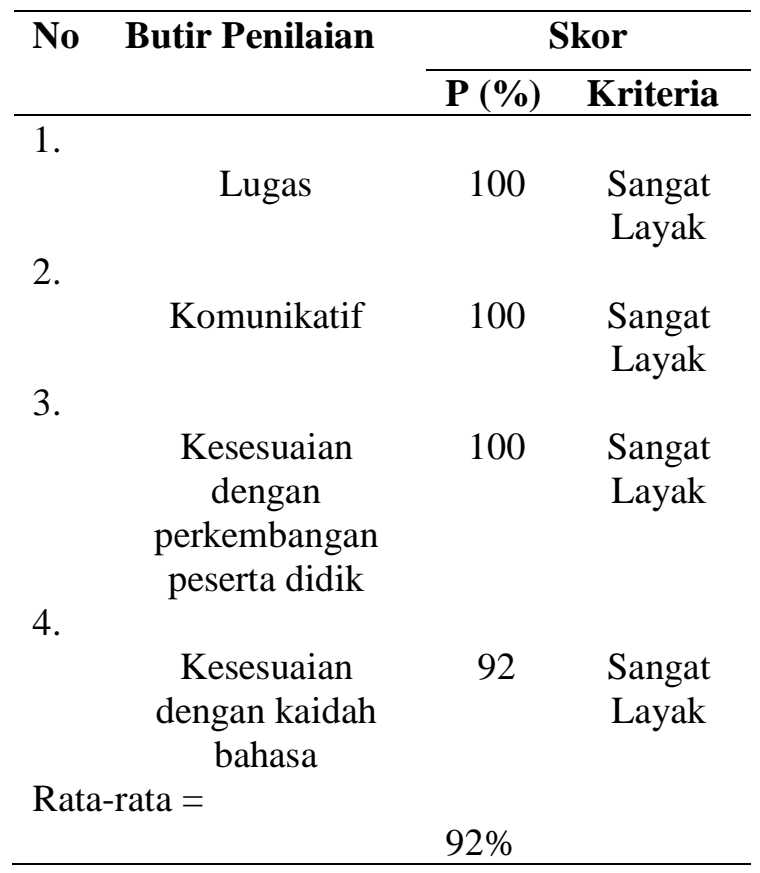

Seluruh indikator memperoleh skor 100 $\%$, terkecuali indikator kesesusaian dengan kaidah bahasa mendapatkan skor 92\%, dengan catatan bagian yang harus diperbaiki pengunaan tanda koma, penggunaan tanda titik, dan preposisi dan mempelajari kembali ejaan bahasa Indonesia terutama pada penggunaan tanda baca yang tepat.

\section{Ahli Grafika}

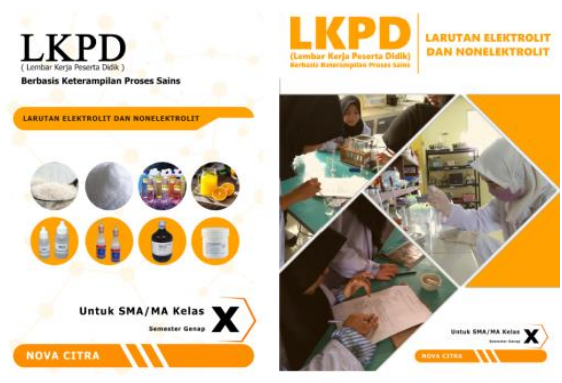

Gambar 2. Revisi Bagian Cover LKPD

Dalam Gambar 2, revisi yang dilakukan adalah gambar pratikum peserta didik yang dapat mengambarkan keterampilan proses sains merupakan gambar yang diambil sen diri bukan bersumber dari internet. Validasi grafik dilakukan oleh tiga orang ahli grafik. Penilaian ahli grafik dilakukan untuk menen tukan tingkat kelayakan grafik pada lembar kerja peserta didik berbasis keterampilan proses sains.

Tabel 3 . Hasil Penilaian Kelayakan Grafik

\begin{tabular}{|c|c|c|c|}
\hline \multirow[t]{2}{*}{ No } & \multirow{2}{*}{$\begin{array}{c}\text { Butir } \\
\text { Penilaian }\end{array}$} & \multicolumn{2}{|c|}{ Skor } \\
\hline & & $\mathbf{P}(\%)$ & Kriteria \\
\hline 1. & $\begin{array}{l}\text { Penggunaan } \\
\text { huruf ( jenis } \\
\text { atau ukuran ) }\end{array}$ & 100 & $\begin{array}{l}\text { Sangat } \\
\text { Layak }\end{array}$ \\
\hline 2. & $\begin{array}{l}\text { Lay Out dan } \\
\text { tata letak }\end{array}$ & 100 & $\begin{array}{l}\text { Sangat } \\
\text { Layak }\end{array}$ \\
\hline 3. & $\begin{array}{l}\text { Ilustrasi } \\
\text { gambar dan } \\
\text { foto }\end{array}$ & 92 & $\begin{array}{l}\text { Sangat } \\
\text { Layak }\end{array}$ \\
\hline & Rata-rata $=$ & & \\
\hline $\begin{array}{l}\text { per } \\
100 \\
\text { fot } \\
\text { LK } \\
\text { ma } \\
\text { seh } \\
\text { dan }\end{array}$ & $\begin{array}{l}\text { Masing-masin } \\
\text { entase dengan } \mathrm{k} \\
\% \text {, kecuali indik } \\
\text { mendapatkan s } \\
\mathrm{D} \text { berbasis ke } \\
\text { h kekurangan } \\
\text { gga saran dar } \\
\text { dilengkapi gar } \\
\text { rampilan proses }\end{array}$ & $\begin{array}{l}\text { ikator } \\
\text { uhan s } \\
\text { lustras } \\
\text { \% kar } \\
\text { pilan } \\
\text { bar u } \\
\text { perlu } \\
\text { di LK }\end{array}$ & $\begin{array}{l}\text { mperoleh } \\
\text { penilaian } \\
\text { mbar dan } \\
\text { di dalam } \\
\text { ses sains } \\
\text { k materi } \\
\text { ambahkan } \\
\text { berbasis }\end{array}$ \\
\hline
\end{tabular}




\section{Ahli Materi}

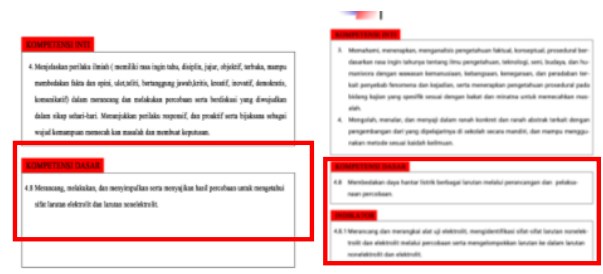

Gambar 3. Revisi Bagian KI dan KD

Berdasarkan hasil review dari ahli materi, pada bagian kompetensi inti masih mengguna kan KI dari KTSP belum menggunakan KI K13, setelah direvisi diganti menjadi KI K13 menyesuaikan dengan kurikulum yang diguna kan di sekolah tempat penelitian dan perlu dicantumkan indikator pembelajaran sehingga memudahkan pembaca mengetahui capaian indikator yang digunakan di dalam LKPD. Validasi yang dilakukan oleh ahli dengan mengamati tiga hal, yaitu kelayakan materi dan penyajian, kelayakan kebahasaan, dan kelayakan kegrafikan.

Tabel 4. Hasil Penilaian Kelayakan Materi

\begin{tabular}{lllc}
\hline No & Butir Penilaian & \multicolumn{2}{c}{ Skor } \\
& & $\mathbf{P}(\%)$ & Kriteria \\
\hline 1. & $\begin{array}{l}\text { Kesesuaian } \\
\text { materi dengan }\end{array}$ & 100 & $\begin{array}{l}\text { Sangat } \\
\text { Layak }\end{array}$ \\
& KD & & Sangat \\
2. & Layak \\
& $\begin{array}{l}\text { Cakupan Materi } \\
\text { Mendorong }\end{array}$ & 100 & \\
Keingitahuan & 100 & $\begin{array}{l}\text { Sangat } \\
\text { Layak }\end{array}$ \\
& Rata-rata $=$ & & $\begin{array}{l}\text { Sangat } \\
\text { Layak }\end{array}$ \\
\hline
\end{tabular}

Seluruh indikator penilaian memperoleh skor $100 \%$ dengan kategori sangat tinggi.

Tabel 5. Hasil Validasi Ahli

\begin{tabular}{|c|c|c|c|}
\hline \multirow[t]{2}{*}{ No } & \multirow[t]{2}{*}{ Aspek kelayakan } & \multicolumn{2}{|c|}{ Skor } \\
\hline & & $P(\%)$ & Kriteria \\
\hline 1. & Bahasa & $100 \%$ & $\begin{array}{l}\text { Sangat } \\
\text { layak }\end{array}$ \\
\hline 2. & Materi & $98 \%$ & $\begin{array}{l}\text { Sangat } \\
\text { layak }\end{array}$ \\
\hline 3. & Grafika & $97,3 \%$ & $\begin{array}{l}\text { Sangat } \\
\text { layak }\end{array}$ \\
\hline \multicolumn{2}{|c|}{ Rata-rata } & $98,43 \%$ & $\begin{array}{l}\text { Sangat } \\
\text { Layak }\end{array}$ \\
\hline
\end{tabular}

Berdasarkan data hasil penilaian kelayak an terhadap LKPD berbasis KPS oleh para ahli rata-rata skor total sebesar $98,43 \%$ masuk kedalam kriteria sangat layak.

Tabel 6. Respon Guru Terhadap LKPD Berbasis KPS

\begin{tabular}{|c|c|c|c|}
\hline \multirow[t]{2}{*}{ No } & \multirow{2}{*}{$\begin{array}{c}\text { Butir } \\
\text { Pernyataan }\end{array}$} & \multicolumn{2}{|c|}{ Skor } \\
\hline & & $\mathbf{P}(\%)$ & Kriteria \\
\hline \multirow[t]{7}{*}{1.} & Saya & 100 & Sangat \\
\hline & menyukai & & Tinggi \\
\hline & keseuluran & & \\
\hline & tampilan & & \\
\hline & LKPD & & \\
\hline & berbasis KPS & & \\
\hline & menarik & & \\
\hline \multirow[t]{8}{*}{2.} & Dengan & 91,66 & Sangat \\
\hline & menggunakan & & Tinggi \\
\hline & Dengan & & \\
\hline & menggunakan & & \\
\hline & LKPD & & \\
\hline & berbasis & & \\
\hline & keterampilan & & \\
\hline & proses sains & & \\
\hline \multirow[t]{9}{*}{3.} & Kata-kata & 83,33 & \\
\hline & yang & & Sangat \\
\hline & digunakan & & Tinggi \\
\hline & dalam LKPD & & \\
\hline & berbasis & & \\
\hline & keterampilan & & \\
\hline & proses sains & & \\
\hline & mudah untuk & & \\
\hline & dipahami & & \\
\hline \multirow[t]{7}{*}{4.} & Tulisan di & & \\
\hline & dalam LKPD & 100 & Sangat \\
\hline & berbasis & & Tinggi \\
\hline & keterampilan & & \\
\hline & proses sains & & \\
\hline & dapat dibaca & & \\
\hline & dengan jelas & & \\
\hline \multirow[t]{9}{*}{5.} & LKPD & & \\
\hline & berbasis & 100 & Sangat \\
\hline & keterampilan & & Tinggi \\
\hline & proses sains & & \\
\hline & dapat & & \\
\hline & membantu & & \\
\hline & guru dalam & & \\
\hline & menjelaskan & & \\
\hline & isi LKPD & & \\
\hline \multirow[t]{5}{*}{6.} & Materi yang & 83,33 & Sangat \\
\hline & disajikan & & Tinggi \\
\hline & dalam LKPD & & \\
\hline & berbasis & & \\
\hline & keterampilan & & \\
\hline
\end{tabular}


proses sains

tidak urut

Rata-rata

93,95\% Sangat

Tinggi

Berdasarkan hasil data angket respon guru diperoleh rata-rata sebesar 93,95\% dengan kriteria sangat baik, sesuai dengan hasil penelitian (Nurina \& Rusly, 2019) yang menyata kan validitas respon guru sebesar $83,96 \%$ dengan kriteria sangat layak.

\section{KESIMPULAN}

Berdasarkan hasil penelitian dan pengembangan yang dilakukan, maka dapat di simpulkan bahwa LKPD berbasis Keterampilan proses sains pada materi larutan elektrolit dan nonelektrolit telah layak digunakan di tingkat SMA. Ditinjau dari aspek grafika, bahasa, dan materi memperoleh persentase sebesar 98,2\%. Hasil angket respon guru terhadap lembar kerja peserta didik (LKPD) berbasis keterampilan proses sains pada materi larutan elektrolit dan nonelektrolit dengan persentase $93 \%$ dengan kategori sangat baik.

\section{DAFTAR PUSTAKA}

Ango, M. . (2002). Mastery of Science Process Skills and Their Effective Use in the Teaching of Science An Educology of Science Education in the Nigerian Context. Inter.J.Educol, 1(16), 11-30.

Ardhiaiantari, W. F., \& Kadaritna, N. (2015). Pengembangan LKS Berbasis Keterampil an Proses Sains pada Materi Hukumhukum Dasar Kimia. Jurnal Pendidikan Dan Pembelajaran Kimia, 1(4), 312-323.

Asrizal., Amran, A., Ananda, A., \& Festiyed. (2019). Effects of Science Student Worksheet of Motion in Daily Life Theme in Adaptive Contextual Teaching Model on Academic Achievement of Students. IOP Conf. Series: Journal of Physics: Conf. Series, 1185, 012093, 1-9.

Firdaus, L., \& Hunaepi, H. (2016). Studies Facilitation Acqusition About The Science Process Skills on the 4 Grade Studen Madrasah Ibtida'iyah (MI) NW Kerumut. Jurnal Ilmiah Pendidikan Biologi "Bio scientist,", 4(2), 112-114.
Firdaus, L., \& Mirawati, B. (2017). Keteram pilan Proses Sains Dalam Pembelajaran: Suatu Tinjauan Teoritis. Jurnal MIPA, 2(1), 1-4.

Fitriyani, D., Rahmawati, Y., \& Yusmaniar. (2019). Analisis Pemahaman Konsep Siswa pada Pembelajaran Larutan Elektrolit dan Nonelektrolit dengan 8E Learning Cycle. Jurnal Riset Pendidikan Kimia, 9 (1), 30-40.

Karsli, F., \& Sahin, C. (2009). Developing Worksheet Based on Science Process Skills: Factors Affecting Solubility. In Asian Pacific Forum Sci.Learn and Teach, 1(10), 4-16.

Marsa, Hala, Y., \& Taiyeb, A. M. (2016). Pengaruh Penggunaan Lembar Kerja Peserta Didik Berbasis Pendekatan Ilmiah Terhadap Aktivitas Dan Hasil Belajar IPA Biologi Kelas VII Peserta Didik SMP Negeri 2 Watampone. Jurnal Ilmiah Ilmu Pengetahuan Alam, 5 (1), 42-57.

Muida, D. A. (2019). Pengembangan Lembar Kerja Peserta Didik Berbasis Keterampilan Proses Sains Pada Pembelajaran Biologi SMP kelas VIII. Jurnal Biologi, 132-135.

Nurina, A. Q., \& Rusly, H. (2019). Validitas Lembar Kerja Peserta Didik (LKPD) Berbasis Contextual Teaching and Learning Untuk Melatihkan Keterampilan Berpikir Kritis Pada Materi Larutan Elektrolit Dan Non Elektrolit. Unesa Journal of Chemical Education, 8(3), 294 298.

Rahmatillah., Halim, A., \& Hasan, M. (2017). Pengembangan Lembar Kerja Peserta Didik Berbasis Keterampilan Proses Sains Terhadap Aktivitas pada Materi Koloid. Jurnal IPA dan Pembelajaran IPA, 1(2), 121-130.

Riduwan. (2015). Skala Perguruan VariabelVariabel Penelitian. ALFABETA.

Tawil, L., \& Diella, D. (2019). Pelatihan Pengembangan LKPD Berbasis Keteram pilan Proses Sains dan Penyusun Instru men Asesmen KPS Guru. Jurnal Publikasi Pendidikan, 1(11), 12-26. 